\title{
The linkage of information quality to an executive decision support framework for the financial service sector of a developing economy
}

\begin{tabular}{|c|c|}
\hline \multicolumn{2}{|c|}{$\begin{array}{l}\text { Authors: } \\
\text { Visvanathan Naicker }{ }^{1} \\
\text { Denisha Jairam-Owthar }\end{array}$} \\
\hline \multicolumn{2}{|c|}{$\begin{array}{l}\text { Affiliations: } \\
{ }^{1} \text { Department of Business } \\
\text { Information and } \\
\text { Administration, Cape } \\
\text { Peninsula University of } \\
\text { Technology, South Africa }\end{array}$} \\
\hline \multicolumn{2}{|c|}{$\begin{array}{l}{ }^{2} \text { Graduate School of Business } \\
\text { Leadership, University of } \\
\text { South Africa, South Africa }\end{array}$} \\
\hline \multicolumn{2}{|c|}{$\begin{array}{l}\text { Corresponding author: } \\
\text { Visvanathan Naicker, } \\
\text { naickervi@cput.ac.za }\end{array}$} \\
\hline \multicolumn{2}{|c|}{$\begin{array}{l}\text { Dates: } \\
\text { Received: } 15 \text { Aug. } 2016 \\
\text { Accepted: } 26 \text { Apr. } 2017 \\
\text { Published: } 27 \text { June } 2017\end{array}$} \\
\hline \multicolumn{2}{|c|}{$\begin{array}{l}\text { How to cite this article: } \\
\text { Naicker, V. \& Jairam-Owthar, D., } \\
2017 \text {. 'The linkage of } \\
\text { information quality to an } \\
\text { executive decision support } \\
\text { framework for the financial } \\
\text { service sector of a developing } \\
\text { economy', South African } \\
\text { Journal of Information } \\
\text { Management 19(1), a781. } \\
\text { https://doi.org/10.4102/ } \\
\text { sajim.v19i1.781 }\end{array}$} \\
\hline \multicolumn{2}{|c|}{$\begin{array}{l}\text { Copyright: } \\
\text { (C) 2017. The Authors. } \\
\text { Licensee: AOSIS. This } \\
\text { is licensed under the } \\
\text { Creative Commons } \\
\text { Attribution License. }\end{array}$} \\
\hline \multicolumn{2}{|l|}{ Read online: } \\
\hline 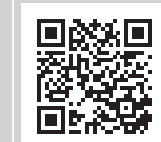 & $\begin{array}{l}\text { Scan this QR } \\
\text { code with your } \\
\text { smart phone or } \\
\text { mobile device } \\
\text { to read online. }\end{array}$ \\
\hline
\end{tabular}

Background: Executives are steering organisations in our most turbulent economic times, whereby market disrupters are becoming the norm that are eradicating entire value chains of organisations. It is for this reason that decision support mechanisms for executives have become more critical than ever before. We have seen many leading organisations being reduced to market followers. This leaves many critical questions: What could the executives of those prior leading organisations have done to prevent this? Does the information that is being presented at various senior committees for decisions in an organisation contain information quality and is information quality linked to decisions made by executives?

Objectives: This article presents mathematical evidence that information quality does form part of an executive decision support framework (EDSF) and confirms that information quality should form part of an EDSF.

Method: A mixed method research approach was then followed where semi-structured interviews were held with chief information officers. The semi-structured interviews thereafter informed the survey questionnaires design. The survey questionnaires were statistically analysed using structural equation modelling and the maximum likelihood estimates method, to mathematically prove if information quality does form part of an EDSF.

Results: This research provides evidence that information quality is linked to an EDSF and that information quality should form part of an EDSF.

Conclusion: It is clear, therefore, that information quality is mathematically linked to an EDSF. Although information quality is made up of other latent variables that affect it, there is a strong correlation between information quality and an EDSF.

\section{Introduction}

Technological advancements have aided the digital era in generating daily gigabytes of information across various channels such as call centres, online portals, mobile phones, podcasts and branch offices (Hauser \& Rouse 2007). However, a major challenge is creating information with quality. Marshall and Harpe (2009) explain that it is only possible to utilise information effectively if the data used to provide the information have quality.

Information quality currently has no industrialised understanding and definitions. Globally different organisations have different understandings and definitions of information quality. However, information quality is critical because information cannot be used if it cannot be trusted. Therefore, information quality is important. The purpose of this research is to ascertain if information quality should form part of executive decision support framework (EDSF) and to prove if information quality is mathematically linked to an EDSF. Other studies have only mentioned that information quality is important with varying classifications of information quality, but none of the previous research studies have incorporated a comprehensive view of various experts to conclude if information quality should form part of EDSF and mathematically endeavours to prove that information quality is linked to an EDSF. This article, therefore, adds value to the body of knowledge by focussing on the above explained aspects.

\section{Literature review}

The literature review will be structured to discuss the following with regard to information quality: definition, significance, challenges, solutions to challenges, evidence of information quality's importance according to experts, relevance of information quality to the financial 
services sector, important components of information quality, EDSFs, limitations, future research and, finally, a summary of the literature review. The current status of the above topics in information quality will be discussed, and thereafter, the limitations and recommendations for future research will be discussed. Reference studies will be mentioned that have made significant reference to information quality in their research. Firstly, however, a brief overview of Company A, which was used as a compelling case for this research study will be provided.

\section{Overview of Company A}

The services sector has direct impact on customers where improvements are needed (Tomlinson 2011). Furthermore, the financial services sector was selected as a compelling case because the recent global economic downturn resulted from a myriad of financial services sector failures that affected customers and economies directly (Crotty 2009). Examples of organisations in the financial services sector that failed economically in their lifecycles were the Lehman Brothers, J P Morgan and Chase, Merrill Lynch and Goldman Sachs.

Company A was once a market leader in South Africa in the financial services sector in which it operates. It had merged with a global company thereafter, expanding its services to the rest of Africa. After the merger took place, a restructuring of Company A occurred. During this transition of alignment, Company A had become a market follower, from a technological and customer-centric perspective.

\section{Definition of information quality}

According to Somers, Gorla and Wong (2010), information quality refers to the quality of outputs the information system produces which can be in the form of reports or online screens. GARP (2011) refers to information quality as being available and containing integrity. Information quality as explained by Goel, Indushobha and Smith (2010) is a multidimensional concept, which can be classified into five major categories: intrinsic quality, contextual quality, representation, accessibility and completeness. The researchers agree that information quality has several aspects to it. Hamblin and Phoenix's (2013) definition of information quality is congruent with Goel et al.'s (2010) that outlines the characteristics of effective information quality as intrinsic data quality, accessibility, contextual quality and timeliness. From the researchers' view, perhaps the most holistic definition is encompassed by Hauser and Rouse (2007) who defines information quality as a state of completeness, validity, consistent and timely to serve for specific business decisions.

These components of Hauser and Rouse's (2007) definition are further explained:

- Completeness: Degree to which values are present in the attributes that require them.

- Consistency: The agreement or logical coherence among data that free them from variation of contradiction.
- Timeliness: The expectation that a particular data item or multiple items are provided at the time requested or specified.

- Validity: Conformance of data values that are edited for acceptability or fall within acceptable ranges of allowable values.

For the purposes of this research, the definition provided by Hauser and Rouse (2007) above will be used, because it provides the most comprehensive coverage of the information quality definition.

\section{Significance of information quality}

A survey was conducted by Somers et al. (2010) for improving information quality because it emerged as one of the top five concerns facing executives. Somers et al. iterate that information quality is highly important to organisations to derive value in terms of improved decision-making and providing accurate and timely information. Fulmer (2012) describes that information quality is the new 'black' because it is the new fashion due to it being the only way to ensure profitability going forward. Cunningham (2012) agrees that the need to ensure information is reliable and authentic and has never been higher. Performance monitoring of information quality is important (Delbaere \& Ferreira 2007).

The researchers duly note that from these authors, therefore that there is a linking of information quality to profitability and performance of companies. Delbaere and Ferreira (2007) agree that information quality can be measured across multiple dimensions, for example, how well a data element meets a company's information integrity goals and needs. Because information quality is a multidimensional measure, it is important to determine which aspects of information are critical to organisations. Somers et al.'s (2010) research portrays that information quality is directly impacted by the information systems quality. According to Somers et al., excellence in information systems quality involves state-of-the-art technology, following industry's 'best practice' software standards and delivering error-free performance.

The researchers argue that a performance metrics to measure information quality, because it is a multidimensional concept, would be beneficial to an organisation to highlight information quality maturity and to focus on improvements. Allen et al. (2011) assert that a business's information is one of its most important assets. Allen et al.'s extensive research has emphasised the strategic value of information. The strategic value together with the advancement and complexity of networking technologies can create opportunities for attacks and security breaches that can cause great financial loss. The researchers emphasise that the link between losses and information highlights the linkage of information quality and information security.

Wang and Chang (2011) agree with the opinion that information security enhances information quality. They explain that a number of information security breaches can cause economic loss. Ezingeard, McFadzean and Birchall 
(2007) support this view by explaining that companies that admit to breaches within their confidential information had a reduction in their stock market price, which can contribute to a financial crisis. Furthermore, Hall, Sarkani and Mazzuchi (2010) found that information security is also significant for information quality.

The researchers agree that information security should form part of information quality as probed by the experts. Hauser and Rouse (2007) are of the opinion that the usual ad hoc information clean-up projects put in place relating to improving quality issues do little to sustain a cultural commitment to information quality across the organisation. The researchers contend that although information security is a key element of information quality, it is not the only element of information quality. The researchers agree as suggested congruently by the authors that there is a need to govern information quality because of its many aspects, through an overarching information policy. The researchers thereby argue that although an information policy and procedure need to be developed within an organisation, effective embedment within the organisation requires an entire culture change throughout the organisation on information itself. A culture change of an organisation as mentioned by Hauser and Rouse requires a holistic strategy, rather than mediocre remediation projects. The researchers highlight that accountability on how information is managed, stored and processed has emerged as a focal area as promulgated by the Protection of Personal Information Act (POPI), soon to be implemented into South African legislation.

Hauser and Rouse (2007) agree the inter-relationship between data, technology, process and people needs to be considered overall for information quality optimisation in an organisation. Hamblin and Phoenix (2013) promulgate that information management goes beyond external stakeholder requirements as there are also a multitude of internal users. From the view of these experts, the researchers assimilate that an overall approach to information quality is encouraged, internally and externally. Ezingeard et al. (2007) agree that although information security is important, information systems specialists lack a common understanding resulting in limited dialogue and inadequate definitions of what comprises successful performance of information quality.

The researchers argue that as a resolution, all definitions should be made clear in the information policy to promote a common understanding, thereafter to allow dialogue towards the performance of successful information quality. Adversities in information quality have negative impact to organisations and users (Cunningham 2012; Iwasaki \& Jones 2010). The researchers, therefore, suggest that a hybrid approach involving people, process and technology is vital to migrate towards a successful information quality culture. The starting elements of driving an information quality culture are introducing dialogue.

The researchers use examples from organisations such as Google, Uber and Facebook, whereby the microcosm of their business is information management. These gigantic organisations possess an advanced organisational culture for information and data management, enabling them to be powerful 'mogul' organisations of our decade. The researchers emphasise that confidence suffers and economic functions underperform when there is uncertainty about the integrity of information. According to Cunningham (2012), events in which data were improperly and illegally manipulated have driven the requirements for ensuring information quality. Cunningham asserts that adverse events, such as security beaches and data reconciliations from different systems, have placed a higher burden on organisations to ensure information quality. The researchers agree with the experts whereby there is an increasing high emphasis on information quality in organisations.

\section{Challenges of information quality}

Various problems and solutions occur in the information quality sphere as discussed below. Poor information quality could have the following impact on organisations as highlighted by different authors in Tables 1 and 2 .

Some solutions which could help resolve some of these issues to aid in database normalisation processes, as mentioned by Iwasaki and Jones (2010), are:

- setting up internal control procedures

- monitoring the implementation of information quality strategy and

\begin{tabular}{lll}
\multicolumn{2}{l}{ TABLE 1: } & Negative strategic impact of poor information quality. \\
\hline Number & Negative Impact & Author \\
\hline 2 & $\begin{array}{l}\text { Incorrect strategic decisions. } \\
\text { Time wasted as data needs to be } \\
\text { reconciled and verified to source before } \\
\text { presentations at meetings. }\end{array}$ & Hamblin and Phoenix (2013) \\
$\begin{array}{l}\text { Unauthorised access to users on } \\
\text { confidential information that could } \\
\text { cause material harm to the organisation } \\
\text { such as reputation damage. }\end{array}$ & Cunningham (2012) \\
\hline 4 & $\begin{array}{l}\text { Slowing the speed of quick decisions that } \\
\text { need to be made. }\end{array}$ & Iwasaki and Jones (2010) \\
\hline 5 & $\begin{array}{l}\text { Lack of seamless linkage between 'siloed } \\
\text { databases' causing duplicates. }\end{array}$ & Hauser and Rouse (2007) \\
6 & $\begin{array}{l}\text { Lack of robustness in estimations for } \\
\text { future trending. }\end{array}$ & Hamblin and Phoenix (2013) \\
7 & $\begin{array}{l}\text { Lack of analytical view of figures. } \\
\text { Inadequate audit trail of information. }\end{array}$ & Hamblin and Phoenix (2013) \\
\hline 8 & Hamblin and Phoenix (2013) \\
\hline
\end{tabular}

Note: Please see the full reference list of the article, Naicker, V. \& Jairam, D., 2017, 'The linkage of information quality to an executive decision support framework for the financial service sector of a developing economy', South African Journal of Information Management 19(1), a781. https://doi.org/10.4102/sajim.v19i1.781, for more information.

TABLE 2: Negative operational and tactical impact of poor information quality.

\begin{tabular}{lll}
\hline Number & Negative impact & Author \\
\hline 1 & Inconsistent data field definitions. & Hauser and Rouse (2007) \\
2 & Multiple shadow or customised databases. & Hauser and Rouse (2007) \\
3 & Duplicate customer records. & Hauser and Rouse (2007) \\
4 & Reduction in reputation. & Ezingeard et al. (2007) \\
5 & Poor customer service. & Ezingeard et al. (2007) \\
6 & Inhibits the firm's ability to operate. & Ezingeard et al. (2007) \\
\hline
\end{tabular}

Note: Please see the full reference list of the article, Naicker, V. \& Jairam, D., 2017, 'The linkage of information quality to an executive decision support framework for the financial service sector of a developing economy', South African Journal of Information Management 19(1), a781. https://doi.org/10.4102/sajim.v19i1.781, for more information. 
- introducing external experts to guide information quality initiatives and projects in the organisation.

Deeper negative underlying items of poor information that culminate holistically into poor information quality are supported by various authors, which are highlighted in Table 2 .

Hauser and Rouse (2007) and Fulmer (2012) suggest some solutions for improvement of the operational and tactical items of poor information quality:

- remove redundant information from databases

- reduce processing time of data

- introduce monitoring processes to resolve quality errors

- design and implement a strategy for information quality management

- enhance quality by implementing data quality processes, roles and responsibilities for compliance, fraud prevention and loss control

- develop suitable information quality measures such as of data integrity mandates, standardisation of data and

- introduce reporting and process controls for end to end information quality management.

The researchers agree and acknowledge the negative impact, both directly and indirectly, that poor information quality can have on an organisation. Information quality issues can, therefore, be at strategic, tactical and operational levels in an organisation (Cunningham 2012; Ezingeard et al. 2007; Hamblin \& Phoenix 2013; Hauser \& Rouse 2007; Iwasaki \& Jones 2010) According to Somers et al. (2010), information quality problems can include system problems such as incorrect information because of program or data errors and irrelevant information because of changed user requirements. They explain that although 50 years of software development has come and gone, software quality today is no better than it was decades ago. They further elaborate that software problems, difficult user interfaces and fragmented models are difficult to integrate data for information quality to be achieved. Therefore, data integration from different systems can compromise information quality (Delbaere \& Ferreira 2007).

The researchers iterate that in industry, a fundamental challenge exists, whereby ownership of data within the systems requires clear understanding. The researchers are of the view that ownership of data can assist in alleviating information quality issues where controls can be instituted by the data owner to manage data integration, data errors and limit duplications. Delbaere and Ferreira (2007) are of the opinion that data emerging from different source systems in different data formats create information quality challenges.

The researchers highlight some challenges posing integrity issues that include collection, reconciliation and integration of data. Hauser and Rouse (2007) agree that fragmented data decrease information quality. Solutions can be implemented such as improving reconciling data from different sources (Iwasaki \& Jones 2010). Achieving the 'one view of the customer' presents a challenge for many financial services industries, as with Company A (i.e. a huge conglomerate in the banking industry in $S A$ ). This is an integral aspect of achieving competitive success with a customer that transacts using many products housed in one financial services institution. Amalgamating information from different products source systems into one source involves data integration. For successful data integration, controls such as reconciliations should be performed to ensure information quality for trust to be built on the outputs of the processed information, as suggested by Delbaera and Ferreira (2007) and with which the researchers agree. Solutions to some challenges in information quality will be highlighted.

\section{Solutions to challenges}

Iwasaki and Jones (2010) propose a solution of using external assurance as one of the ways to enhance credibility to information. They highlighted that the benefit of this is primarily to enhance confidence of information for the benefit of its users who have little control over its production. Ezingeard et al. (2007), however, explains that there is no universally accepted definition on what constitutes 'information assurance'. Nonetheless 'information assurance' is a strategic issue because of the potential impact on the rest of the business, for example, a decrease in stock market price.

The researchers emphasise that trust of presented information to executives needs to be built. One of the methods as part of the journey of building trust of the information is reconciliations as mentioned by Delbaera and Ferreira (2007). The researchers are of the view that reconciliations, therefore, can be automated as a form of 'information assurance'. The researchers argue that although external assurance maybe a solution, the practical feasibility to have external assurers available to check every report that has tight deadlines, to be sent to executive management, may not be possible. However, it may be feasible for external assurers to be used for external reports only, to be provided for external stakeholders of the organisation. The researchers are of the view that external reports being produced for external stakeholders to some extent rely in internal information or reports (e.g.: corporate sustainability projects that the organisation is carrying out for the community where information is found within the organisation to report this to external stakeholders). However, as emphasised prior, external assurance on every report may not always be practically achievable because of costs and timeliness for the organisation.

\section{Evidence of the importance of information quality according to experts}

Fulmer (2012) presents an example with evidence on information quality that cost lenders of mortgage loans close to US\$2 trillion in direct loses because of foreclosures, 
settlements with residential mortgage backed securities investors, repurchases and regulatory fines. He explains that the data quality is the foundation that supports sustainable loans. The most important revenue generator in some financial services organisations is obtained from lending products, as with Company A (for anonymity).

The researchers argue that achieving information quality would, therefore, serve as a critical success factor for the financial services sector, in support of Fulmer's (2012) view for attaining sustainable income for the organisation. Surveys conducted in Leon et al.'s (2012) research show that most organisations have no formal policies to ensure integrity of information. Leon et al. revealed that companies reported, while informal guidelines were common, formal guidelines existed in only half of the 43 companies in total that were surveyed. The researchers are of the view that the awareness of information quality in companies have increased in 2015. The researchers provide instances of growing increase, whereby the current financial services organisations such as the large banks in South Africa have dedicated business units within the information technology departments whereby information quality is starting to be managed. The SarbanesOxley regulations hold publicly trading companies in the USA accountable for implementing and evaluating controls for reporting to reduce risk. Hauser and Rouse (2007) explain that public companies throughout USA have increasing levels of scrutiny because of the Sarbanes-Oxley regulation where senior executives are required to take a more active interest in the accuracy and timeliness of their data.

The researchers note, however, that the Sarbanes-Oxley regulations are not legislation in developing economies. Carly Fiorina, the former chairperson of Hewlett-Packard, explains that information obtained is meaningful only if it is accurate. In her collective experience, she states that quality of information once reports are compiled in many organisations are below acceptable standards (Mattix \& Henning 2010). Hauser and Rouse (2007) confirm via their empirical studies that organisations do not lack information, but they lack high-quality information. These authors continue to suggest that 'siloed data' result in poor-quality information where organisations suffer through decreased customer retention, decreased customer profitability and decreased product market maturity by using cross-sell or up-sell techniques. The researchers agree with the experts on the criticality of information quality within organisations. Information quality which serves as a catalyst for the financial services sector will be elaborated on next.

\section{Relevance of information quality to the financial services sector}

The relevancy of information quality in the financial services sector is explained further (Fulmer 2012; Iwasaki \& Jones 2010). Fulmer explains that there are inconsistencies in data between information submitted by the borrower of mortgage loans and information obtained from other independent sources such as credit bureaus. Loans with variances must be investigated and corrected before the loan is approved, and lending forms an integral part of generating profits for banks. Therefore, Fulmer claims that data integrity for information quality is imperative for mortgage lenders.

The researchers acknowledge, therefore, that mortgage loan products are, therefore, vital for the banking industry as it generates a substantial amount of profits in the form of interests charged on loans, whereby data integrity is critical. Iwasaki and Jones (2010) iterate that the financial services sector is important to the market economy as even though the overall contribution to the gross domestic product is relatively small; its impact on capital flows is fundamental. When the world-wide economic crisis occurred, the usefulness of auditors in the banking sector were in question. The researchers argue, however, as stated prior that the practicality of using auditors, also classified as external assurers, may not always be possible for all management reports. The components of information quality are discussed in detail below.

\section{Important components of information quality}

Somers et al. (2010) explain that information quality has a data quality component because data quality is at the heart of information quality. The authors continue to explain that poor data quality results in poor information quality. The ripple effect being, poor information quality adversely affecting the organisation at all levels. Selection and execution of sound business strategy becomes difficult because of inaccurate or delayed information, causing strategic drift. Delbaere and Ferreira (2007) also link information quality to data integrity. They advocate that data integrity involves maintaining the quality of information throughout the organisation.

Delbaere and Ferreira (2007) elaborate that information quality also includes how effectively data support decisions as highlighted in the proposed research study. They refer to decision support that is needed to meet organisations strategic objectives, for executive and senior management decisions.

The researchers, therefore, argue that at the heart of information quality lies data quality and integrity, whereby information quality is largely dependent on data quality and integrity. Wang and Chang (2011) go further to dissect information security, which forms part of information quality such as confidentiality, integrity and availability. Wang and Chang explain that the confidentiality aspect is information that remains safe from any unauthorised access and has not been subject to modification and forgery.

Wang and Chang (2011) further outline that information availability refers to the extent to which information is readily accessible. The researchers agree, therefore, that information 
accessibility can also form as part of the information security component of information quality. Li and Chang (2007) explain that organisational culture must be aligned for effective information security in the organisation. $\mathrm{Li}$ and Chang's research findings, however, suggest that cooperativeness negatively affects confidentiality. Confidentiality as outlined by Wang and Chang (2011) is crucial for information security. Therefore, enterprises should adopt an integrated strategy combining both information security and organisation culture aspects.

The researchers highlight as prior per above that a people, process and technology integrated approach is important for enhancing information quality in an organisation. Hauser and Rouse (2007) explain that one of the major components for information quality is a centralised source of customer data for the organisation. However, the dreams of a single source of truth have not always been realised because of the variation across source systems (Hauser \& Rouse 2007). Hauser and Rouse refer to adversities such as systemic errors that are difficult to eradicate and further investment maybe needed to cleanse data and integrate sources. This supports GARP's (2011) view which states that there are various duplicate sources of information which creates doubt on the correctness of the information presented.

The researchers iterate that this forms part of the data integration problem across different systems for achieving information quality as mentioned prior. There are new proposed solutions to information quality and there are still challenges to be addressed if information quality is to be enhanced by information assurers (Hamblin \& Phoenix 2013). Elements of information assurance for managing information quality, according to Hamblin and Phoenix, comprise of standard definitions to be developed, trialled and implemented to ensure a common data language exists through the organisation.

Page (2011) is of the opinion that for data and information quality, the organisation should have a corporate wide agenda for data, a joint effort between business and the information technology unit of the organisation and an evolutionary process throughout the company to support quality. Differences must be identified and the underlying reasons elicited and resolved for an institutional standard for information assurance (i.e. an information policy for information assurance for improving information quality) to be implemented (Hamblin \& Phoenix 2013).

The process for information assurance, however, must avoid over checking and substantial costs but provide sufficient frequency for integrity, objectivity and independence with executive management support (Hamblin \& Phoenix 2013). Therefore, from the above experts, the researchers argue that a correct balance must be established between costs and information quality through information assurance. In support of this view, Hamblin and Phoenix explain that although this is a new proposed solution of 'information assurance', there are specific challenges that come with this solution such as practical feasibility and costs.

Therefore, information assurance may not provide the solution to compromised information quality. An integrated approach to information across the organisation as mentioned by Page (2011) above presents a more feasible and practical solution. A summary of the literature review on information quality will now be provided.

\section{Executive decision support framework}

The literature on EDSFs as compared to developed disciplines such as medicine and engineering which are more than 2000 years old is still to be developed. It is important to note that even in developed disciplines such as engineering and medicine, EDSFs are still recommended for further research within these advanced disciplines although EDSFs may already be in use in these areas.

The young discipline of specifically Executive Decision Support Systems is only 35 years old which provides an opportunity through this research to add to the body of knowledge (Davis, Keenan \& Power 2013). Being able to investigate a key component such as information quality and mathematically prove their linkages for an EDSF is therefore a value add to the body of knowledge. EDSF is defined for the purposes of this research as a framework that would support executives in their decision-making.

\section{Summary of information quality literature review}

Information quality is made up of several components and is of high relevance to the financial services sector. Information quality is significant for providing trustworthy information to executive and senior management. Although there are challenges to information quality, solutions have been evidenced. From this literature review, it can, therefore, be noted that information quality is a key component of an EDSF. The arrow showing the information transfer control below. Hence, emanating from the above literature reviewed, the following research question was conceptualised.

'Should information quality form part of an executive decision support framework?' and 'Is information quality mathematically linked to an executive decision support framework?'

\section{Research methodology}

A research methodology was conducted as per Figure 1 that was used to assess if information quality does indeed form part of an EDSF for decision support for executives.

The research paradigm consisted of a pragmatic approach per the epistemology and ontology because of a mixed methods research methodology. It was conducted using a 
case study of Company A, which is an organisation in the financial services sector of a developing economy. A deductive research logic because theory was looked at first, as per the theoretical default framework above. The time horizon was cross sectional because of time and resource constraints of the researchers.

The mixed method approach methodology consisted of semistructured interviews as the qualitative aspect. The reason a mixed method methodology was used was to ensure high validity and high reliability of the conducted research, because quantitative and qualitative research is deals with high validity and high reliability respectively. Semi-Structured interviews were held using a purposive sample with the four chief information officers (CIO's) to obtain depth of knowledge and context, before the survey questionnaires could be designed.

The results of the semi-structured interviews were thereafter used to inform the quantitative aspect per the survey questionnaires. The semi-structured interviews were conducted using a voice recorder and interview notes. The survey questionnaires were then designed and piloted among nine persons across the organisation before the survey questionnaires could be finalised for distribution. This pilot was done to ensure the questionnaires were understood by participants. No major corrections on the survey questionnaires resulted after the pilot was conducted.

The survey questionnaire was in the form of a Likert scale. The population consisted of 706 persons in total because of the total number of senior and executive managers across the organisation. Thereafter proportional sampling techniques were performed to carry out the survey questionnaires to ensure a stratified sample response across the divisions in the organisation.

The results of the semi-structured interviews were analysed and synthesised using themes and counting techniques, to ensure all input was included for consideration into the survey questionnaires. The analysed feedback was then inputted into the formation of the survey questionnaire. The survey questionnaires were handed out manually and sent via email to participants to increase response rates. A reminder for survey responses had to be sent via email to

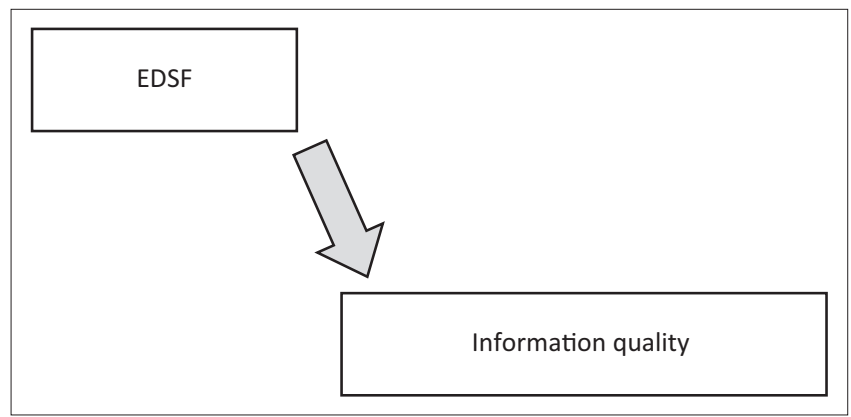

FIGURE 1: Proposed linkage between the two constructs: Information quality and executive decision support framework. participants to ensure an increased response rate across the divisions, which is summarised in Table 4.

The results of the survey questionnaires after the survey questionnaire was conducted, were inferentially analysed using SPSS and IBM AMOS computer software to identify trends and patterns because the SPSS and IBM AMOS software has more accuracy than manual analysis of trends and patterns. Thereafter descriptive statistics were used to represent the results emerging from the survey questionnaires using bar graphs and/or pie charts.

Triangulation of results took place by the researcher to increase the validity and reliability of the research, through manually comparing the results emanating from the semistructured interviews to the survey questionnaires. This provided in-depth triangulation outcome results after the comparison of the data was completed. High validity was maintained using the qualitative semi-structured interviews and high reliability was maintained using the quantitative survey questionnaires, therefore, confirming the choice of a mixed method methodology of maintaining high results in both validity and reliability of the research.

Ethics throughout the research process was maintained. For the statistical analysis, structural equation modelling was used for validity and reliability of the research; and the maximum likelihood estimates method were used to show if the constructs were mathematically related.

\section{Results}

The semi-structured interviews are summarised in the figures below which highlights the common themes and outlying themes for every construct from the CIOs from each division of Company A.

As from Table 3 a common thread is data accuracy, data governance, differing reports and business being responsible for information. As aligned with the literature review, information quality consists of many elements of which not

TABLE 3: Information quality survey results summarised, September 2015 - A: Information quality.

\begin{tabular}{lcc}
\hline Theme & Common & Outliers \\
\hline Accuracy & $\mathrm{X}$ & - \\
Never really understood & - & $\mathrm{X}$ \\
Technically based on business rules & - & $\mathrm{X}$ \\
Accuracy and integrity & $\mathrm{X}$ & - \\
Information quality depends on business requirements & $\mathrm{X}$ & - \\
Business's responsibility & $\mathrm{X}$ & - \\
Business's responsibility: Accepts remediation projects & $\mathrm{X}$ & - \\
Affects clients directly: one view of the client & - & $\mathrm{X}$ \\
Data volumes & $\mathrm{X}$ & - \\
Legacy system integration & - & $\mathrm{X}$ \\
Data governance needs improvement & $\mathrm{X}$ & - \\
Reports differ & $\mathrm{X}$ & - \\
Users have source system access, minimum use of warehouse & - & $\mathrm{X}$ \\
Too many spreadsheets & $\mathrm{X}$ & - \\
Meta data, master data management, data linage, reference data & - & $\mathrm{X}$ \\
\hline
\end{tabular}


all employees in organisations are completely clear on (GARP 2011; Goel et al. 2010; Hamblin \& Phoenix 2013; Somers et al. 2010). It is interesting to note that data governance and volumes which lead to a data-driven culture, also came up as common themes. This highlights that a data culture is important to harness as recommended by the experts (Hauser \& Rouse 2007).

\section{Geographic and demographics analysis}

The respondents to this survey totalled one hundred and seven $(n=107)$ bank officials. Those in the Retail and Business Bank divisions accounted for $43 \%$ of respondents, the remainder comprised: Corporate and Investment Banking, 17.8\%; Financial Services Insurance $14.0 \%$ and Enterprise Support Services $25.2 \%$. Almost all of the respondents are based in South Africa (99.1\%) while the remainder (0.9\%) are from Barclays Africa (12 countries). The respondents in South Africa amounted to $99.1 \%$ (Table 4).

As compared to the initial sample frame of 141 respondents at the onset of the research per the research methodology; there was a $76 \%$ response rate. There was no initial sample target set for respondents in South Africa. However, as stated, most respondents were from South Africa, that is, $99.1 \%$. Retail and Business bank had a targeted response rate of $19.7 \%$; the actual response rate achieved was $43 \%$. Corporate and Investment Banking had a targeted response rate of 20\%; $17.8 \%$ was actually achieved. Financial Services Insurance was initially allocated a $20 \%$ response rate target; a $14 \%$ actual response rate was achieved. Enterprise Support Services was initially allocated a $20 \%$ response rate and achieved a 25.2\% response rate. Retail and Business Banking and Enterprise Support Services had an increased response rate of $24 \%$ (i.e. $43 \%-19.7 \%$ ) and $5.5 \%$ (i.e. $25.2 \%-20 \%$ ) respectively, based on the initial sample frame. Corporate and Investment Banking and Financial Services Insurances had a decreased response rate of $2.2 \%$ (i.e. $20 \%-17.8 \%$ ) and $6 \%$ (i.e. $20 \%-14 \%$ ) respectively. An overall summary of responses will be provided next.

\section{Overall summary of responses}

The questionnaire outcomes are summarised in Table 5.

Most of the sample population 'agreed' or 'strongly agreed' with the questions on information management. The questions on information management were positioned from the literature review and the semi-structured interviews, thereby in practice participants have 'agreed' and 'strongly agreed'.

\section{Structural equation modelling for validity and reliability}

To evaluate reliability of the measurement items by determining how participants interpreted the questions per category, Cronbach's alpha with an acceptable value of 0.70 as confirmed by Hair et al. (2009) was calculated and confirmed to be greater than the recommended value of 0.70 (Table 6).

\section{Maximum likelihood estimates}

Information quality was analysed to ascertain how much it contributes to an EDSF using the statistical method of maximum likelihood estimates. This is summarised in Table 7.

\section{Limitations}

A selected case study was used, therefore, it would be irresponsible to generalise outside the financial services sector. Confidentiality was of the selected case had to be maintained because of the high competitive nature of Company A. Although generalizability is not random, the outcomes can be transferable to any other case exhibiting similar characteristics to that of company A.

Feedback for the research methodology was obtained only from senior and executive management because time for the research study did not permit other levels of management such as operational and tactical management to be included. Provided that this is an EDSF, this seems fair.

TABLE 5: Frequency distribution of the overall opinion on information management.

\begin{tabular}{lcc}
\hline Option & Frequency & $\mathbf{\%}$ \\
\hline Disagree & 1 & 0.9 \\
Neutral & 4 & 3.7 \\
Agree & 72 & 67.3 \\
Strongly agree & 30 & 28 \\
\hline Total & $\mathbf{1 0 7}$ & $\mathbf{1 0 0}$ \\
\hline
\end{tabular}

TABLE 6: Structural equation modeling for validity and reliability.

\begin{tabular}{lcccc}
\hline Construct & $\begin{array}{c}\text { Instrument } \\
\text { (questionnaire) }\end{array}$ & $\begin{array}{c}\text { Number of } \\
\text { items (number } \\
\text { of questions) }\end{array}$ & $\begin{array}{c}\text { Cronbach's } \\
\text { alpha }\end{array}$ & $\begin{array}{c}\text { Number of } \\
\text { valid sample }\end{array}$ \\
\hline $\begin{array}{l}\text { Information } \\
\text { management }\end{array}$ & $\mathrm{A} 1-\mathrm{A} 22$ & 22 & 0.833 & 100 \\
\hline
\end{tabular}

TABLE 7: Maximum likelihood estimates results.

\begin{tabular}{lccccc}
\hline Relationship & Estimate & SE & CR & $p$-value & Label \\
\hline IQ and EDSF & 0.108 & 0.030 & 3.535 & $* * *$ & $\mathrm{c} 1$ \\
\hline
\end{tabular}

IQ, information quality; EDSF, executive decision support framework; SE, standard error; $C R$ critical ratio.

Note: The asterisks in the $p$-value column of the table, illustrate a strong correlation between these constructs: IQ and EDSF. The model equations in the structural framework are therefore, as follows: IQ $=0.108 \mathrm{EDSF}+Z 1$. IQ is made up of 0.108 of EDSF. Z1 represents al other aspects that constitute IM.

TABLE 4: Percentage response from each division of Company $A$

\begin{tabular}{|c|c|c|c|c|}
\hline Area & Frequency & $\%$ & Valid (\%) & Cumulative $(\%)$ \\
\hline Retail and Business bank & 46 & 43 & 43 & 43 \\
\hline Corporate and investment banking & 19 & 17.8 & 17.8 & 60.7 \\
\hline Company A financial services (insurance) & 15 & 14 & 14 & 74.8 \\
\hline Enterprise Support Services (IT, risk, compliance, HR, finance) & 27 & 25.2 & 25.2 & 100 \\
\hline Total of each area & 107 & 100 & 100 & Not applicable \\
\hline
\end{tabular}




\section{Future research}

It is recommended that other sectors of developing economies can conduct this research, such as engineering and the public sector. Future research is also recommended to determine the impact that an EDSF with information quality has on other levels of management such as operational and tactical management. The impact that information quality has on the board of directors of a company can also be researched further. Behavioural changes once information quality is implemented throughout an organisation can also be researched in future.

\section{Conclusion}

There have been several challenges with information quality such as incorrect strategic decisions which may result in time wasted on data that needs reconciliation for verification purposes before decisions can be made, lack of trends and estimations that may result and a lack of an audit trail of information. Information quality has several components, which executive and senior management require in order for information to be trusted for decision-making and thereby is of high relevance to the financial services sector. Because IQ is not an industrialised concept as explained in the literature review, the understanding of this construct may not be as advanced in Africa and South Africa.

As per the research questions mentioned above: 'Should information quality form part of an executive decision support framework?' and 'Is information quality mathematically linked to an executive decision support framework?'

From the literature review it can clearly be noted that information quality is critical and should form part of an EDSF, because information that cannot be trusted cannot be used for decisions. This is supported throughout the literature review by various expert views which were also supported by the researcher's views. This research also proves that information quality is mathematically linked to an EDSF via the statistical analysis done with structural equation modelling and maximum likelihood estimates conducted through the mixed method research methodology. No other research proves a mathematical link between these constructs, although much prior research refers to the importance of information quality only, without specificity to an EDSF. The purpose and objective of this research has been met from answering the set questions above.

\section{Acknowledgements}

The authors gratefully acknowledge the editor and reviewers' constructive comments on an earlier version of the article.

\section{Competing interests}

The authors declare that they have no financial or personal relationships that may have inappropriately influenced them in writing this article.

\section{Authors' contributions}

D.J. and V.N. are the project leaders of this study. They made conceptual contributions to this study. Calculations were performed by an independent paid statistician. This article emanated from D.J.'s doctoral thesis.

\section{References}

Allen, J.P., Karlsson, F., Kolkowska, E. \& Hedstrom, K., 2011, 'Value conflicts for information security management', Elsevier Journal of Strategic Information Systems 20, 373-384. https://doi.org/10.1016/j.jsis.2011.06.001

Crotty, J., 2009, 'Structural causes of the global financial crisis: A critical assessment of the new financial architecture', Cambridge Journal of Economics 33(4), 562-580.

Cunningham, P., 2012, 'GARP focus', Information Management Journal 9(2), 21-22.

Davis, B.G., Keenan, P. \& Power, D.J. 2013, 'History of decision support systems', viewed 03 August 2013, from http://dssresources.com/history/dsshistory.html

Delbaere, M. \& Ferreira, R., 2007, 'Addressing the data aspects of compliance with industry models', IBM Systems Journal 46(2), 319-334. https://doi.org/10.1147/sj.462.0319

Ezingeard, J.N., McFadzean, E. \& Birchell, D., 2007, 'Mastering the art of corroboration: A conceptual analysis of information assurance and corporate strategy alignment' Emerald Journal of Enterprise Information Management 20(1), 96-118. https:// doi.org/10.1108/17410390710717165

Fulmer, A., 2012, 'Is data integrity the new black', ABI Inform Complete Mortgage Banking 72(9), 23-25.

Generally Accepted Record Keeping Principles (GARP), ARMA International, 2011, 'Protect and maintain information integrity to decrease business risk', Information Management Journal 3, 37-40.

Goel, S., Indushoba, N. \& Smith, C., 2010, 'Metrics for characterizing the form of security policies', Elsevier Journal of Strategic Information Systems 19, 281-295. https://doi.org/10.1016/j.jsis.2010.10.002

Hair, J.F., Black, C.W., Barry, B.J., Anderson, E. \& Tatham, R.L., 2009, Multivariate data analysis: A global perspective, 7th edn., Prentice Hall, Upper Saddle River, NJ.

Hall, J.H., Sarkani, S. \& Mazzuchi, T.A., 2010, 'Impacts of organisational capabilities in information security', Emerald Information Management and Computer Security Journal 19(3), 155-176. https://doi.org/10.1108/09685221111153546

Hamblin, D.J. \& Phoenix, D.A., 2013, 'A model for managing data assurance in higher education', Journal of Higher Education Policy and Management 34(4), 421-435. https://doi.org/10.1080/1360080X.2012.689195

Hauser, S.A.M. \& Rouse, C., 2007, 'The whole truth and nothing but the truth? The role of data quality today', Direct Marketing: An International Journal 1(3), 161-171. https://doi.org/10.1108/17505930710779333

Iwasaki, J. \& Jones, M., 2010, 'Governance benefits of new assurance reports', International Journal of Disclosure and Governance 8(1), 4-15.

Leon, L., Kalbers, L., Coster, N. \& Abraham, D., 2012, 'A spreadsheet life cycle analysis and the impact of Sarbanes-Oxley', Elsevier Decision Support Systems 54 452-460. https://doi.org/10.1016/j.dss.2012.06.006

Li, C.S. \& Chang, S.E., 2007, 'Exploring organisational culture for information security management', Emerald Industrial Management and Data Systems 107(3), 438-458. https://doi.org/10.1108/02635570710734316

Marshall, L. \& Harpe, D.L.R., 2009, Decision making in the context of business intelligence and data quality, Cape Peninsula University of Technology, Published by InterWord Communications for the Department of Information and Knowledge Management, University of Johannesburg, Pretoria.

Mattix, M. \& Henning, S., 2010, 'Ensuring data integrity', Claims Magazine, 02 April, p. 27

Page, J., 2011, 'How to launch data governance initiative', Business Intelligence Journal 16(2), 17-25. https://doi.org/10.1016/j.jsis.2010.05.001

Somers, M.T., Gorla, N. \& Wong, B., 2010, 'Organisational impact of system quality, information quality and service quality', Elsevier Journal of Strategic Information Systems 19, 207-228.

Tomlinson, R.M. 2011. 'Managing the risk in housing delivery: Local Government in South Africa', Elsevier Habitat International 35(3), 419-425.

Wang, C.P. \& Chang, K.C., 2011. 'Information systems resources and information security', Information Systems Front, Department of Information Management $13,579-593$. 